\title{
Reply to Miller on agendas and sincerity
}

\author{
Thomas Schwartz
}

Received: 31 May 2010 / Accepted: 4 August 2010 / Published online: 29 September 2010

(C) The Author(s) 2010. This article is published with open access at Springerlink.com

\begin{abstract}
Contrary to Miller, Farquharson's agenda trees do omit real parliamentary information. And the assumptions he uses to justify Farquharson's definition of sincere (or naive) voting justify too little (e.g., he drops maximax) and rule out too much (e.g., non-pre-set agendas and principled sincere voting).
\end{abstract}

Keywords Agendas · Sincerity · Voting

In his response to Appendix II of my 2008 article on parliamentary procedure, Miller (2010) concedes three things: (1) My agenda trees do contain more information than Farquharson's (1969). (2) My definition of sincere voting is "simpler and more direct" than Farquharson's. (3) Farquharson's maximax rule is not essential to sincere voting. There remain some finer points of disagreement. But first let me commend Miller for his rich history of the subject: it lets us see the forest for the trees.

On agendas, suppose we have a bill $b$ and two amendments, producing amended bills $a$ and $c$, the second introduced only if the first loses. My arboreal version of the agenda is (1a) (of Miller's Fig. 1). Switch $b$ with $c$ and you have (1d). Miller equates them by recasting both as the Farquharsonian (1b), or equivalently (1c). That destroys information because, among other things, (1a) and (1d) begin with different choices: $a$ versus $b$ under (1a), $a$ versus $c$ under (1d).

Miller agrees but denies that this difference is a "parliamentary" one. For (1a) and (1d) begin, he says, with the same "question": "Shall the amendment $a$ be adopted?" No, the "question" must include more. It must specify the bill to be amended: $b$ in the one case, $c$ in the other. It must also specify how to amend it - what and where to add, strike, or substitute. That part of the "question," too, is different under the two agendas because the specified alterations are performed on different main motions.

T. Schwartz $(\bowtie)$

Department of Political Science, UCLA, 4289 Bunche Hall, Box 951472, Los Angeles,

CA 90095-1472, USA

e-mail: tschwartz@polisci.ucla.edu 
As for sincerity (or naivité), suppose sincere Rep. McX prefers $c$ to $a$ to $b$ to $q$. At (1a)'s first vote he would vote for the amendment by my definition because he prefers $a$ to $b$. But by Farquharson's he would vote against it because (1) his "real" choice is between the sets $\{a, q\}$ and $\{b, c, q\}$ of all outcomes achievable following positive or negative votes on the amendment and (2) McX prefers $\{b, c, q\}$ to $\{a, q\}$ according to the maximax rule: $\{b, c, q\}$ has the better best member ( $c$ rather than $a$ ).

Even if McX compares those sets, why use optimistic maximax? No reason, Miller now concedes. Instead, he says, McX might use pessimistic (lexicographic) maximin and favor $\{a, q\}$. But why stop there? Maybe McX is neither an optimist nor a pessimist but sees each set as an even-chance lottery and compares their expected utilities. At any rate, by insisting that sincere legislators compare two sets but not saying how, Miller no longer has a definition of sincere voting.

And why compare those sets, rather than $a$ and $b$ ? In part because Miller restricts his universe to pre-set agendas, as I called them-ones whose alternatives have all been formally introduced before voting begins. I expressly rejected that restriction because it bars too many agenda forms. For example, the U.S. House allows only a handful of pre- set forms, not including (1a) (Sullivan 1984). (By the way, the allowed forms are all complete, and for them my definition of sincere voting coincides with Farquharson's.) Miller likes pre-set agendas because he thinks that strategic voting requires them anyway, so legislators can look ahead to the bottom of the tree and reason back according to majority preferences. Sincere legislators, too, can look ahead from atop pre-set agendas and see the likes of $\{b, c, q\}$ and $\{a, q\}$. But they cannot reason back, says Miller, so they can only compare sets, because they do not know majority preferences. That is the one and only difference, he contends, between them and strategic legislators.

I disagree. First of all a legislator might be able to look ahead even when the agenda is not pre-set. Sometimes legislators broadcast their intent to offer amendments, occasionally by pre-filing, and often enough voters make educated guesses or have inside information. Neither is the one and only difference between sincere and strategic legislators that the latter know majority preferences. On the one hand, outside the tiny pre-set universe, strategic legislators might have better information about future motions. On the other hand, sincere legislators need not be ignorant of majority preferences or anything else. In Riker's (1986: 10-17) famous story of the 1902 U.S. Senate vote on the direct election of senators, every senator knew enough to vote strategically. Even so, western Republicans voted sincerely, not strategically, for DePew's killer amendment, written to protect black voters, because a negative vote would have offended their constituents-and maybe their consciences. If nonstrategic sincere voting were solely the creature of ignorance, strategic voting would never have posed the dilemma that it does sometimes pose for principle versus expediency.

In his final example, Miller tries to turn the tables on my own final example (concocted to show how silly Farquharsonian sincere voting can be) by supposing, under agenda (1a), that "everyone loves $c$ and despises all the other alternatives." But even if only the majority party felt that way, $c$ would end up on the agenda beneath $a$ as well as $b$. So Miller's example does not fit (1a) - and if we alter (1a) by adding $c$ beneath $a$, there is no longer a difference between sincere voting in Farquharson's sense and mine.

Sincere and strategic voting mark behavioral extremes. Sincere legislators compare alternatives from the top down, as in a decision tree, strategic legislators from the bottom up, as in a game tree. Strategic legislators fully anticipate both future motions and future votes, sincere legislators neither, sometimes because they cannot (they lack information), sometimes because they would not if they could (they think it wrong to do so). Between those extremes lie countless interesting hybrid types. Farquharson and Miller's hybrids anticipate 
motions but not votes. Another type anticipate votes stochastically, based on a distribution over preferences. Yet another anticipate votes on foreseen (or pre-announced) motions but not surprise motions. And that is a bare beginning. I assumed the two extremes because they are so simple, distinct, and mathematically tractable, and even assuming them the actual content of the chief forms of parliamentary procedure had never before been studied.

Open Access This article is distributed under the terms of the Creative Commons Attribution Noncommercial License which permits any noncommercial use, distribution, and reproduction in any medium, provided the original author(s) and source are credited.

\section{References}

Farquharson, R. (1969). Theory of voting. New Haven: Yale University Press.

Miller, N. (2010). Agenda trees and sincere voting: a response to Schwartz. Public Choice, 145, xx-xx.

Riker, W. H. (1986). The art of political manipulation. New Haven: Yale University Press.

Schwartz, T. (2008). Parliamentary procedure: principal forms and political effects. Public Choice, 136, 353377.

Sullivan, T. (1984). Procedural structure. New York: Praeger. 